\title{
Correction to: Validation of the Aldosteronoma Resolution Score Within Current Clinical Practice
}

\author{
Wessel M. C. M. Vorselaars ${ }^{1} \cdot$ Dirk-Jan van Beek ${ }^{1} \cdot$ Emily L. Postma $^{1} \cdot$ Wilko Spiering $^{2}$ • \\ Inne H. M. Borel Rinkes ${ }^{1} \cdot$ Gerlof D. Valk $^{3} \cdot$ Menno R. Vriens ${ }^{1} \cdot$ International $^{1}$ \\ CONNsortium Study Group
}

Published online: 5 September 2019

(C) The Author(s) 2019

\section{Correction to: World J Surg https://doi.org/10.1007/s00268-019-05074-z}

In the original article, two of the International CONNsortium Study Group collaborator's names are spelled wrong: Anton F. Engelsman and Els J.M. Nieveen van Dijkum. The spellings are correct as reflected here.
Publisher's Note Springer Nature remains neutral with regard to jurisdictional claims in published maps and institutional affiliations.

The original article can be found online at https://doi.org/10.1007/ s00268-019-05074-z.

\section{Menno R. Vriens}

mvriens@umcutrecht.nl

1 Department of Surgical Oncology and Endocrine Surgery,

University Medical Center Utrecht, Room G04.228,

Heidelberglaan 100, 3584 CX Utrecht, The Netherlands

2 Department of Vascular Medicine, University Medical Center Utrecht, Utrecht, The Netherlands

3 Department of Endocrine Oncology, University Medical Center Utrecht, Utrecht, The Netherlands 